\title{
Strategies for improving use of text-matching software by staff
}

\author{
Miriam Sullivan and Miela Kolomaznik \\ Curtin University, KeyPath Education
}

\begin{abstract}
Universities are increasingly requiring the use of text-matching software (e.g., Turnitin, Urkund) for assessment. Even so, teaching staff may be resistant to using new technology for a variety of reasons. This study aimed to determine specific strategies and recommendations for improving uptake and correct usage of text-matching software at universities by gathering the experiences of training staff who have combatted resistance to new technologies. Two focus groups with 22 participants across five universities used a modified version of the Delphi method to come to consensus on their top five recommended strategies, which included: offering "out of the box" materials, using evidence, fostering champions, providing training and support to teaching staff, ensuring consistent messaging, building relationships, and offering student-facing support. These strategies may help university trainers improve the adoption of text-matching software, though more research is needed to determine the relative effectiveness of different strategies.
\end{abstract}

Keywords: developing digital fluency, text-matching, Turnitin, resistance to change, leading change

\section{Background}

Increasingly, universities are mandating the use of text-matching software (e.g., Turnitin, Urkund) through institutional policy. The Australian Government Tertiary Education Quality and Standards Agency (TEQSA) recommends using text-matching software with particular settings or practices (e.g., to allow students multiple submissions prior to a deadline) to safeguard academic integrity, "protect students' learning outcomes, institutional reputations, educational standards, professional practice, and public safety" (TEQSA, 2017, p. 1).This is generally considered to be a positive shift: such software has been shown to improve students' paraphrasing skills, reduce marking time, standardise marking practices, and increase equal access to feedback (Buckley, 2013; Halgamuge, 2017; Penn \& Wells, 2017; Stone, 2014). However, we often suspect that teaching staff are not fully complying with the spirit of the policy (e.g., Stowe, 2017) due to a number of barriers (Table 1). Trainers (including learning designers, educational technologists, and academic services staff) are often responsible for convincing teaching staff (including academics, lecturers, and tutors) to use new technologies and address policy compliance.

Despite the range of research into why staff do not adopt new technology, there is a dearth of information about what universities or trainers can do to address the problem. Some of the papers suggest techniques to use in developing staff, but it is not the focus of the research. For example, the studies that found workload was an important barrier suggest simplifying processes as much as possible (Morris \& Carroll 2016) and just-in-time individual support for staff, rather than workshops (Watty, Mkay \& Ngo, 2016). However, White et al. (2016) suggested that workshops were helpful for establishing common ground.

Overall, converting staff to a new technology or policy appears to be a slow, ongoing process. Blin and Munro (2008) argue that training alone is unlikely to be sufficient, and that 'more radical transformations of the overall social and cultural context' are needed (p. 489). Morris and Carroll's (2016) work on introducing a comprehensive academic integrity policy to their institution suggests it takes 3-5 years to develop a community where barriers are properly addressed.

While an iterative, institutional-wide program to fully support staff is the ideal, it is not the reality for most trainers. Trainers need strategies to help teaching staff in using technology even when policy is patchy or nonexistent, and teaching staff are tired and resistant to change. This study aimed to gather the experiences of trainers who have combatted resistance to new technologies to determine specific strategies and recommendations for improving uptake and correct usage of text-matching software at universities. 
Table 1: Barriers to the uptake of new teaching technologies at universities

\begin{tabular}{|l|l|}
\hline Problem & Description \\
\hline Philosophical & $\begin{array}{l}\text { Staff might have philosophical objections to the role of third-party software and how } \\
\text { text-matching fits with their job role. For example, lecturers may not think it is } \\
\text { appropriate that Turnitin keeps assignments, since they are the intellectual property of } \\
\text { the student (Bruton \& Childers 2017). Other lecturers believe it is not their role to } \\
\text { "police students" or that plagiarism detection is not part of their teaching } \\
\text { responsibilities (de Maio, Dixon \& Yeo, 2019). }\end{array}$ \\
\hline Technical Skills & $\begin{array}{l}\text { Many lecturers lack the technical skills to use new software, and resist learning new } \\
\text { technology because they find it difficult (Watty, McKay \& Ngo, 2016). A common } \\
\text { manifestation is using 'rules of thumb' to interpret text-matching reports because they } \\
\text { do not understand how the program works. For example, Palmer (2018) found that half } \\
\text { of the lecturers surveyed used 15\% as an acceptable originality score, and Mphahlele } \\
\text { and McKenna (2019) found that arbitrary cut-offs were even embedded in some } \\
\text { universities policies. }\end{array}$ \\
\hline Workload & $\begin{array}{l}\text { Even if staff are willing to learn new software, they often lack the time to do so (de } \\
\text { Maio, Dixon \& Yeo, 2019; Morris \& Carroll 2016; Watty, McKay \& Ngo, 2016). } \\
\text { Tutors are not always paid for the extra time to check originality reports, and lecturers } \\
\text { do not have workload for reporting students when they are caught cheating. }\end{array}$ \\
\hline Policy & $\begin{array}{l}\text { University staff report being exhausted by constant policy and software changes. Many } \\
\text { staff also disagree with or lack faith in university misconduct processes or policy, so } \\
\text { they choose not to report students (de Maio, Dixon \& Yeo, 2019). }\end{array}$ \\
\hline Resistance to Change & $\begin{array}{l}\text { Lecturers normally develop a consistent method of teaching, and then add new } \\
\text { technology without changing their underlying habits and miss out on the full } \\
\text { functionality of the software (Blin \& Munro, 2008). }\end{array}$ \\
\hline
\end{tabular}

\section{Methods}

We conducted two focus groups, one at the Academic Language and Learning Conference (Fremantle, Western Australia, 2019) and one with staff at a university in Perth, Australia. Overall, 22 staff from 5 universities shared their strategies. The participants had a diverse range of teaching experience and worked in both student and staff facing roles at their institutions. Participants were a convenience sample, who attended based on their interest in the topic. This sampling method allowed for participants to self-select for this topic which requires a relatively niche experience or professional interest. The focus groups ran for 1.5 hours each.

The focus groups were used to "maximise the collection of high quality information in the little time available" (Acocella, 2011, pg1127). Each focus group followed the Delphi method, which normally uses a series of structured questionnaires to solicit a consensus agreement from a group of experts (reviewed in Okoli \& Pawowski 2004). Our focus groups were run using a modified version of the Delphi method based on in-person discussion cycles to generate consensus (Dick, 2000). This method is useful for developing consensus in problem-solving activities (Dick, 2000. Participants were introduced to the topic and warmed up by brainstorming strategies for buying a new car. We gave them feedback on the warm up activity to encourage them to name specific strategies and techniques (e.g., take a test drive, ask a friend), rather than vague generalisations (e.g., do research).

Participants were then given ten minutes in silence to individually generate as many strategies as possible for convincing staff to use a new teaching technology. The participants were asked to focus on their experience with text-matching software, but could also write down strategies they had used in other situations. Each new strategy was written on an index card. At the end of the silent working time, the index cards were shuffled together in small groups (3-4 participants). The group discussed the strategies they had listed on the index cards, combined ones that were similar and ranked them in a rough order of perceived usefulness. Each group then shared their list with the entire focus group and justified their choices. The other groups and facilitators provided feedback and asked questions probing their decisions. The small groups then had another chance to refine their list and change, re-order or add information to their strategies. Each focus group then had to rank their top five strategies for enabling change. 
Thematic content analysis (following Terry et al., 2017) was used draw out semantic (descriptive) codes to compare the consensus strategies between the different groups, and examine the similarities and differences of opinion. Further re-readings of the cards used inductive (latent) coding to draw other re-occurring strategies and patterns from the suggestions that were not explicitly recognised by the groups.

\section{Results}

The focus groups generated 139 cards. Three strategies were ranked as the most effective by both focus groups: 1) creating out of the box materials, 2) using evidence, and 3) fostering champions. Several other strategies were consistently raised and discussed within small groups, but not always placed in the top five strategies. The strategies are described in Table 2.

Table 2: Key strategies identified by the focus groups

\begin{tabular}{|c|c|c|}
\hline Theme & Description & Examples \\
\hline $\begin{array}{l}\text { Out of the box } \\
\text { materials }\end{array}$ & $\begin{array}{l}\text { Providing materials that staff can use straight } \\
\text { away or put on the LMS for students, such as } \\
\text { instructions for tutors or QuickMark banks. }\end{array}$ & $\begin{array}{l}\text { Materials that academics can use in the LMS and } \\
\text { teaching } \\
\text { Point staff to online resources on how } \\
\text { to use Turnitin } \\
\text { Provide the equipment that they need }\end{array}$ \\
\hline Use evidence & $\begin{array}{l}\text { Specific data or evidence showing that } \\
\text { Turnitin is effective. }\end{array}$ & $\begin{array}{l}\text { Show evidence (academic papers) } \\
\text { Get data, e.g., analytics on student use of Turnitin } \\
\text { at the institution } \\
\text { Demonstrate how much time can be } \\
\text { saved marking } \\
\text { Outline the benefits for students }\end{array}$ \\
\hline $\begin{array}{l}\text { Foster } \\
\text { champions }\end{array}$ & $\begin{array}{l}\text { Try to socially norm the program by using } \\
\text { teaching staff as examples or champions. }\end{array}$ & $\begin{array}{l}\text { Testimony from trusted colleagues or peers } \\
\text { Told them who else is doing it } \\
\text { Show examples of TII working for others like } \\
\text { them } \\
\text { Find the head of the discipline group } \\
\text { and have them advocate for training }\end{array}$ \\
\hline $\begin{array}{l}\text { Provide } \\
\text { training and } \\
\text { support }\end{array}$ & $\begin{array}{l}\text { Workshops, at-elbow support and other forms } \\
\text { of direct training. }\end{array}$ & $\begin{array}{l}\text { Offer 24/7 support } \\
\text { Group workshops } \\
\text { How-to guides with step by step instructions }\end{array}$ \\
\hline $\begin{array}{l}\text { Consistent } \\
\text { messaging }\end{array}$ & $\begin{array}{l}\text { The importance of ensuring that leadership, } \\
\text { policy and trainers promoted the same } \\
\text { message. }\end{array}$ & $\begin{array}{l}\text { Make each staff member's role clear } \\
\text { Consistent messaging re: Turnitin - "percentage } \\
\text { is meaningless on its own" }\end{array}$ \\
\hline $\begin{array}{l}\text { Relationship } \\
\text { building }\end{array}$ & $\begin{array}{l}\text { Spending time talking to academics and } \\
\text { building individual relationships. }\end{array}$ & $\begin{array}{l}\text { Start with small talk and get to know them first } \\
\text { Use "we" language, acknowledge and } \\
\text { agree with complaints when true to build } \\
\text { relationship } \\
\text { Bring cake/coffee/food }\end{array}$ \\
\hline
\end{tabular}




\begin{tabular}{|l|l|l|}
\hline $\begin{array}{l}\text { Student facing } \\
\text { support }\end{array}$ & $\begin{array}{l}\text { Bypassing staff and going directly to } \\
\text { supporting the students. }\end{array}$ & $\begin{array}{l}\text { Turnitin practice site } \\
\text { Explain to students how to use it and get them to } \\
\text { discuss it with the lecturer/tutor }\end{array}$ \\
\hline
\end{tabular}

In addition to these themes, we discovered some additional commonalities across responses through the inductive analysis. Overall, the respondents were overwhelmingly positive and understood the viewpoint of teaching staff, even when it made their own jobs more difficult. Themes such as 'Relationship building' and 'Out of the box materials' demonstrated how our participants empathised with the difficulties and workload faced by staff. Many responses focused on the need to make the teaching staff comfortable, such as, "reassure this is a safe environment for learning". Others responses were metacognitive reminders for trainers to be empathic, such as, “don't assume that it's easy for them just because it's so easy for you" and "avoid painting them as irrationally resistant to tech". This positivity is best summarised by the response, "When talking to resistant staff, focus on realistic optimism and humour - fight grumpiness with smiles".

Many participants also raised the issue of institutional culture. Strategies put forward include involving teaching staff in widespread testing; avoiding "insisting" people use specific tools if there is no benefit to adopting a single tool at the institutional level; and setting expectations in position descriptions, job interviews, staff meetings and professional development. However, most respondents felt they had little power over institutional culture so this theme tended to shift towards the specific strategies of "Foster champions" and "Consistent messaging" by the end of the session.

\section{Discussion}

The themes raised by our participants consistently addressed the barriers identified in the literature which prevent teaching staff from effectively using text-matching software. For example, technical skills barriers can be addressed with training and support strategies; workload problems with out of the box materials; philosophical objections with evidence; and policy and resistance to change with consistent messaging, fostering champions, and relationship building. Our participants identified specific strategies within each theme which can offer practical ideas for addressing resistance to new technologies such as Turnitin at universities.

Many participants (who were professional staff themselves) believed that academic staff, in particular, were more likely to be swayed by peers rather than professional staff. This belief may reflect an underlying tension (or perception of tension) between academic and professional staff (Szekeres, 2011; Martin \& Sorensen, 2014; Gray, 2015), though our participants did not explore the source of their belief in detail. They advocated for strategies such as recruiting discipline champions, sharing examples of successful use of text-matching software in units, and getting peers to testify to the usefulness of the software. While our focus groups identified this as one of their most successful strategies, Baughan (2013) found that academic champions for academic integrity struggled with the same types of resistance and barriers to change that the non-academic trainers found. This strategy should therefore be used with care to ensure we are not simply passing the problem onto other staff.

Although training and support were frequently mentioned as a theme, there was little agreement on specifically what sort of training should be provided. Even when participants were encouraged to choose one form of support, they could not decide on their preferred method. In particular, there was a debate between quality and quantity between workshops and at-elbow support. Participants liked workshops because they reach many people simultaneously, which was a more efficient use of time for the trainer. However, one-on-one support was frequently cited as "feeling" the most impactful because the trainer could immediately see behavioural change had taken place. Some proponents of one-on-one training also suggested it was best because academics could "build up confidence" privately with the trainer, without having to admit lack of knowledge in front of any peers. Some suggestions revolved around "doing it for them [academics]", which indicates there are differing ideas of what at-elbow support means.

One focus group was particularly interested in supporting students directly. For example, providing students with direct access to a text-matching portal unlinked to any particular unit, so that students could check and submit their assignment multiple times when the lecturer set their unit to 'one submission only'. This strategy provided a solution for students when teaching staff did not use text-matching software in line with recommendations or policy (e.g., TEQSA, 2017), but doesn't actually address the underlying problem of staff 
engaging with the technology. More research needs to be done to explore whether bypassing teaching staff to support students directly has an impact on staff engagement with or perception towards new technologies.

Although university policy was a key feature in the literature and was discussed by both focus groups, it was not selected as one of the top five themes for either group. Our participants felt that policy was part of the solution, particularly in providing consistent messaging and winning over staff who were already compliant and open to new technology. However, for staff who were resistant to new technology citing policy had not been found to be helpful, and was even found to increase resistance. This is similar to de Maio, Dixon and Yeo's (2019) study on plagiarism policy, which showed that if academics feel they lack autonomy and discretion as a result of a policy they are more likely to diverge from the policy. Morris and Carroll (2016) also stress that changing policy may not change practice. Our participants generally felt they had little control over university policy and culture, and empathised with the challenges faced by teaching staff.

We frequently questioned participants about how they knew which strategy was effective. Participants broadly relied on "what felt good", on-the-spot feedback and responses from teaching staff, and what was considered to be efficient for the trainer's workload. Our participants admitted that they had done little formal evaluation of the effectiveness of their techniques, and discussed the difficulty of evaluating specific training strategies, particularly for the relationship building theme.

In conclusion, both the literature and our experienced participants emphasised the top strategy for enlisting acceptance and compliance with using new technologies like Turnitin is to create common purpose between staff (users and trainers). To achieve this, it helps to understand their perspective. Other top strategies include giving users materials so they can use the technology easily "out of the box"; use evidence to counter their objections; and fostering champions and social norming to increase compliance. However, more research needs to be done to formally evaluate the effectiveness various training strategies.

\section{References}

Acocella, I. (2011). The focus groups in social research: Advantages and disadvantages. Quality \& Quantity. 46, 1125-1136.

Australian Government Tertiary Education Quality and Standards Agency. (2017). Good practice note: Addressing contract cheating to safeguard academic integrity. https://www.teqsa.gov.au/latest- news/publications/good-practice-note-addressing-contractcheating-safeguard-academic

Baughan, P. (2013). The missing meso: Variation in staff experiences of an academic practice initiative and lessons for educational change. International Journal for Educational Integrity, 9(1), 89-100.

Blin, F., \& Munro, M. (2008). Why hasn't technology disrupted academics' teaching practices? Understanding resistance to change through the lens of activity theory. Computers \& Education, 50(2), 475-490.

Bruton, S., \& Childers, D. (2016). The ethics and politics of policing plagiarism: A qualitative study of faculty views on student plagiarism and Turnitin ${ }^{\circledR}$. Assessment \& Evaluation in Higher Education, 41(2), 316-330.

de Maio, C., Dixon, K., \& Yeo, S. (2019). Responding to student plagiarism in Western Australian universities: the disconnect between policy and academic staff. Journal of Higher Education Policy and Management, $1-15$.

Buckley, E. \& Cowap, L. (2013). An evaluation of the use of Turnitin for electronic submission and marking and as a formative feedback tool from an educator's perspective. British Journal of Educational Technology. 44(4), 562-570. DOI:10.1111/bjet.12054

Dick, B. (2000) Delphi face to face. http://www.aral.com.au/resources/delphi.html

Englund, C., Olofsson, A.D., \& Price, L. (2017). Teaching with technology in higher education: Understanding conceptual change and development in practice. Higher Education Research \& Development, 36(1), 73-87.

Gray, S. (2015). Culture clash or ties that bind? What Australian academics think of professional staff. Journal of Higher Education Policy and Management. 37(5), 545-557. 
Halgamuge, M. N. (2017). The use and analysis of anti-plagiarism software: Turnitin tool for formative assessment and feedback. Computer Applications in Engineering Education, 25(6), 895-909.

Martin, B., \& Sorensen, M.J. (2014). Confronting academic snobbery. Australian Universities' Review. 56(2), 64-68.

Morris, E. J., \& Carroll, J. (2016). Developing a sustainable holistic institutional approach: Dealing with realities 'on the ground' when implementing an academic integrity policy. Handbook of Academic Integrity, 1-11.

Mphahlele, A., \& McKenna, S. (2019). The use of turnitin in the higher education sector: Decoding the myth. Assessment \& Evaluation in Higher Education, 44(7), 1079-1089.

Okoli, C., \& Pawlowski, S. D. (2004). The Delphi method as a research tool: An example, design considerations and applications. Information \& management, 42(1), 15-29.

Palmer, A. (2018). Plagiarism in the Digital Era: A Study of Australian Transnational Higher Education in Singapore (Doctoral dissertation, The University of Western Australia).

Penn, P., \& Wells, I. (2017). Enhancing Feedback and Feed-Forward via Integrated Virtual Learning Environment Based Evaluation and Support. Psychology Teaching Review, 23(2), $60-65$.

Prosser, M., Martin, E., Trigwell, K., Ramsden, P. \& Middleton, H. (2008). University academics' experience of research and its relationship to their experience of teaching. Instructional Science, 36, 3-16.

Stone, A. (2014) Online assessment: What influences students to engage with feedback? The Clinical Teacher. 11: 284-289

Stowe, S. (2017). Will they or not? Online faculty intentions to report student plagiarism. Academy of Educational Leadership Journal. 21, 1.

Szekeres, J. (2011). Professional staff carve out a new place. Journal of Higher Education Policy and Management. 33(6), 679-691.

Watty, K., McKay, J., \& Ngo, L. (2016). Innovators or inhibitors? Accounting faculty resistance to new educational technologies in higher education. Journal of Accounting Education, 36, 1-15.

White, P.J., Larson, I., Styles, K., Yuriev, E., Evans, D.R., Rangachari, P.K., Short, J.L., Exintaris, B., Malone, D.T., Davie, B., Eise, N., McNamara, K., \& Naidu, S. (2016). Adopting an active learning approach to teaching in a research-intensive higher education context transformed staff teaching attitudes and behaviours. Higher Education and Development, 35(3), 619-633.

Sullivan, M. \& Kolomaznik, M. (2020). Strategies for improving use of text-matching software by staff. In S. Gregory, S. Warburton, \& M. Parkes (Eds.), ASCILITE's First Virtual Conference. Proceedings ASCILITE 2020 in Armidale (pp. 20-25). https://doi.org/10.14742/ascilite2020.0126

Note: All published papers are refereed, having undergone a double-blind peer-review process.

The author(s) assign a Creative Commons by attribution licence enabling others to distribute, remix, tweak, and build upon their work, even commercially, as long as credit is given to the author(s) for the original creation.

(C) Sullivan, M. \& Kolomaznik, M. 2020 